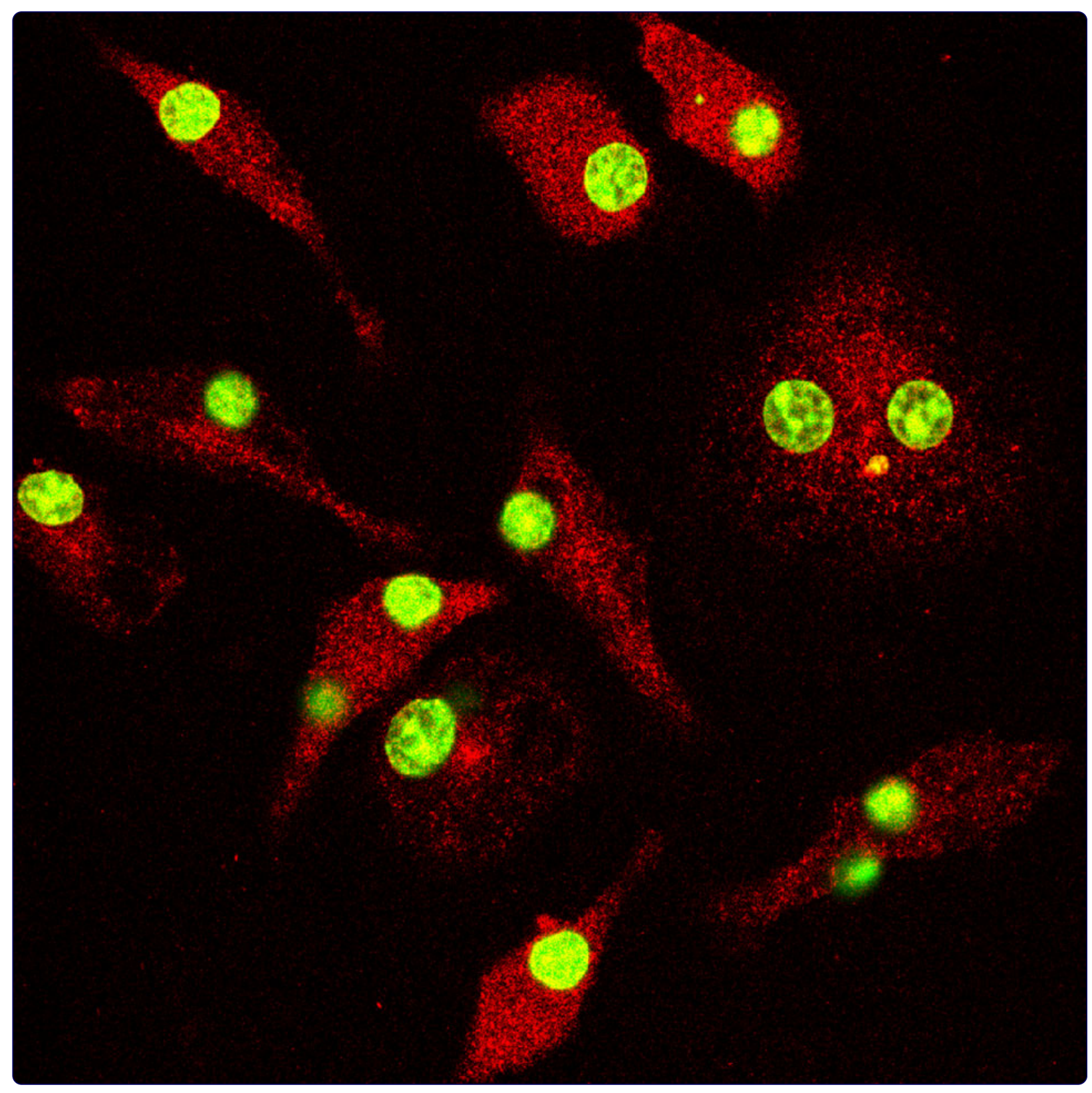

The gamma chain subunit of Fc receptors is required for alpha-synuclein-induced pro-inflammatory signaling in microglia

Cao et al. 


\title{
The gamma chain subunit of Fc receptors is required for alpha-synuclein-induced pro-inflammatory signaling in microglia
}

\author{
Shuwen Cao, David G Standaert and Ashley S Harms*
}

\begin{abstract}
Background: The protein alpha-synuclein (a-SYN), which is found in the Lewy bodies of dopamine-producing (DA) neurons in the substantia nigra (SN), has an important role in the pathogenesis of Parkinson's disease (PD). Previous studies have shown that neuroinflammation plays a key role in PD pathogenesis. In an AAV-synuclein mouse model of PD, we have found that over-abundance of a-SYN triggers the expression of NF-kB p65, and leads to microglial activation and DA neurodegeneration. We also have observed that $F c y$ receptors ( $F \subset \gamma R)$, proteins present on the surface of microglia that bind immunoglobulin $\mathrm{G}(\mathrm{lgG})$ and other ligands, are key modulators of a-SYN-induced neurodegeneration.

Methods: In order to study the role of FcyRs in the interactions of a-SYN and microglia, we treated the primary microglial cultures from wild-type (WT) and $\mathrm{FCYR}^{-/-}$mice with aggregated human a-SYN in vitro.

Results: Using immunocytochemistry, we found that a-SYN was taken up by both WT and FcyR ${ }^{-1-}$ microglia, however, their patterns of internalization were different, with aggregation in autophagosomes in WT cells and more diffuse localization in $\mathrm{FCYR}^{-1-}$ microglia. In WT microglia, a-SYN induced the nuclear accumulation of NF-KB p65 protein and downstream chemokine expression while in $\mathrm{FCYR}^{-1-}$ mouse microglia, a-SYN failed to trigger the enhancement of nuclear NF-kB p65, and the pro-inflammatory signaling was reduced.

Conclusions: Our results suggest that a-SYN can interact directly with microglia and can be internalized and trafficked to autophagosomes. FcyRs mediate this interaction, and in the absence of the gamma chain, there is altered intracellular trafficking and attenuation of pro-inflammatory NF-KB signaling. Therefore, blocking either FcyR signaling or downstream NF-kB activation may be viable therapeutic strategies in PD.
\end{abstract}

Keywords: Neuroinflammation, FcyR, NF-kB, Microglia

\section{Background}

Parkinson's disease (PD) is a degenerative neurological disorder characterized primarily by loss of dopaminergic (DA) neurons from the substantia nigra pars compacta (SNpc). Genetic and biochemical evidences have established a close link between the protein alpha-synuclein $(\alpha-S Y N)$ and the pathogenesis of the disease [1,2]. The disease may be triggered by mutations or overexpression of $\alpha-S Y N$, and all cases of PD are associated with accumulation of insoluble $\alpha$-SYN $[2,3]$. The most prominent

\footnotetext{
* Correspondence: anharms@uab.edu

Center for Neurodegeneration and Experimental Therapeutics, Department of Neurology, The University of Alabama at Birmingham, 1719 th Ave. South, CIRC 516, Birmingham, AL 35294-0021, USA
}

neuropathological features, intraneuronal Lewy bodies and Lewy neurites, are composed mainly of fibrillar $\alpha$-SYN [1]. However, the mechanism by which excess and modified $\alpha$-SYN leads to the degenerative process in PD is still unclear.

Neuroinflammation plays an important role in the pathogenesis and progression of PD. Microglial activation and T-lymphocyte infiltration are consistently observed in the SN of PD patients and in the animal models of PD [4-6]. Meanwhile, cytokines like tumor necrosis factor alpha (TNF- $\alpha$ ), interleukin 1-beta (IL-1b), and interleukin 6 (IL-6) show increased concentration in the serum and cerebrospinal fluid of PD patients [7]. Moreover, a genome-wide association study has shown

\section{Biomed Central}


that polymorphisms in HLA-DR are associated with sporadic PD [8-10]. In previous studies, we have used a mouse model in which $\alpha-S Y N$ is overexpressed using an adeno-associated viral vector (AAV) to reproduce many of these features, including IgG deposition, classical microglial activation with increased production of proinflammatory cytokines, and B- and T-lymphocyte infiltration in the SN [11]. The prominence of this inflammatory response to $\alpha-S Y N$ overexpression has led us to explore the mechanisms responsible for $\alpha$-SYN-induced immune activation.

Fc gamma receptors $(\mathrm{Fc} \gamma \mathrm{R})$ are proteins expressed on the surface of microglia as well as other cell types, including natural killer cells, neutrophils, and mast cells. They bind to immunoglobulin $\mathrm{G}$ (IgG) and some non-IgG ligands, such as complement receptors and C-reactive proteins [12-14], and can trigger microglial activation and cellular responses. In our previous studies in vivo, we have found that the Fc receptors appear to have a key role in $\alpha$-SYN-induced inflammation: deficiency of FcyRs blocks $\alpha$-SYN-induced NF- $\mathrm{kB}$-driven pro-inflammatory signaling, and attenuates microglial activation and DA neurodegeneration [15].

In order to study whether excess $\alpha$-SYN interacts directly with microglia and what role FcyRs play in this process, we treated the primary microglia of wild-type (WT) and $\mathrm{Fc} \gamma \mathrm{R}^{-1-}$ mice with human $\alpha-\mathrm{SYN}$ in vitro. We found that microglia can internalize aggregated $\alpha-S Y N$, and this leads to activation of NF- $\mathrm{kB}$ signaling with downstream induction of chemokines. This process is modulated by Fc $\gamma$ Rs, even in the absence of IgG. These data show that $F c \gamma$ Rs play a role in the interaction of microglia with aggregated $\alpha-\mathrm{SYN}$, and targeting these interactions may be useful in modifying the inflammatory state in PD.

\section{Methods}

Animals

C57BL/6 mice and $\mathrm{Fc} \gamma \mathrm{R}^{-/-}$mice were used for the study. The Fc $\gamma \mathrm{R}^{-/-}$mice in a C57BL/6 background were obtained from Taconic labs (model \# 000583-M-M, Taconic, Hudson, NY, USA). These mice (nomenclature: B6.129P2Fcer1 ${ }^{\text {tm1Rav }}$ N12) are deficient in the gamma chain subunit which is found in several members of the Fc family: FcyRI, FcyRIII, and FceRI. They exhibit immune system defects such as inability to phagocytose antibody-coated particles, and the inflammatory responses to immune complexes are attenuated [16]. All experiments were carried out in compliance with the USPHS Guide for Care and Use of Laboratory Animals. All experiments were approved by the Institutional Animal Care and Use Committee (IACUC) of The University of Alabama at Birmingham with Animal Protocol Number 100908919.

\section{Mouse primary microglia culture and a-SYN treatment}

Microglia were isolated from postnatal day 0 to 3 (P0-P3) C57BL/6 mice and $\mathrm{Fc} \gamma \mathrm{R}^{-/-}$mouse pups according to published protocols [17] with minor modifications. In brief, whole brains were isolated, minced, and placed in ice-cold dissociation media containing sterile filtered DNase1 (1 $\mu \mathrm{L} / \mathrm{mL}$, Invitrogen, Carlsbad, CA, USA), Dispase II (1.2 U/mL, Roche, Indianapolis, IN, USA), and Papain (1 mg/mL, Sigma-Aldrich, St. Louis, MO, USA) dissolved in DMEM/F12 (Sigma-Aldrich, St. Louis, MO, USA). Cells were dissociated for $10 \mathrm{~min}$ at $37^{\circ} \mathrm{C}$ with agitation every few minutes. After mechanical and chemical dissociation, the population of mixed glial cells was filtered through a $40 \mu \mathrm{m}$-pore filter (BD Falcon, Franklin Lakes, NJ, USA) and plated on T75 flasks in DMEM/F12 supplemented with $20 \%$ heat-inactivated fetal bovine serum (FBS, Sigma-Aldrich, St. Louis, MO, USA), 1\% penicillin/streptomycin (Sigma-Aldrich, St. Louis, MO, USA), and 1\% L-glutamine (Sigma-Aldrich, St. Louis, MO, USA). Mixed glial cultures were maintained in culture in a humidified incubator at $37^{\circ} \mathrm{C}$ and $5 \% \mathrm{CO}_{2}$ for 14 to 16 days and media were replenished every 3 to 4 days. Once cultures reached confluence, primary microglial cells were isolated from the astroglial cell bed by mechanical agitation on an orbital shaker $(150 \mathrm{rpm})$ for $1 \mathrm{~h}$ at $37^{\circ} \mathrm{C}$. After isolation, cells were plated in DMEM/F12 supplemented with $1 \%$ penicillin/streptomycin and $1 \%$ L-glutamine at a density of 70,000 cells/ well in a four-well chamber slide (LAB-TEK, Rochester, NY, USA) for immunocytochemistry, ELISA, and multiplex assay.

Purified human $\alpha$-SYN (1 mg/mL, r-Peptide, Athens, GA, USA) was incubated at $37^{\circ} \mathrm{C}$ with agitation for 7 days as previously described [18], and pulse sonicated for $2 \mathrm{~s}$ before adding into the primary microglia culture. In order to determine the aggregated state of the $\alpha-S Y N$ used in these experiments, aliquots of the $\alpha$-SYN preparation were separated on Superdex Column into $1 \mathrm{~mL}$ fractions. All fractions were analyzed by western using a monoclonal antibody (LB509, Abcam, Cambridge, MA, USA) for human $\alpha$-SYN. Western analysis indicated aggregates of approximately $1 \mathrm{MDa}$ (Additional file 1 : Figure S1). The primary microglia were treated with $500 \mathrm{nM}$ aggregated human $\alpha$-SYN at different time points.

\section{Immunocytochemistry}

Twenty-four, 48, and $72 \mathrm{~h}$ after $\alpha$-SYN treatment, antiCD45 and anti-human $\alpha$-SYN antibodies were used to study $\alpha-S Y N$ internalization and localization. For examining NF- $\mathrm{KB}$ activation, we used anti-NF- $\mathrm{kB}$ p65 antibody and SYTOX Green nucleic acid stain for primary microglia $24 \mathrm{~h}$ and $72 \mathrm{~h}$ post treatment.

Cells were fixed with $4 \%$ paraformaldehyde, permeabilized with TBS containing 3\% gelatin from cold water 
fish skin (Sigma-Aldrich, St. Louis, MO, USA), 1\% BSA, and $0.5 \%$ Triton X-100, blocked with TBS containing 3\% gelatin from cold water fish skin and 1\% BSA. Primary antibody incubations were done for $2 \mathrm{~h}$ at room temperature with primary antibodies diluted in TBS containing antibody diluent (TBS containing 3\% gelatin from cold water fish skin, $1 \%$ BSA, and $0.1 \%$ Triton X-100), rat anti-CD45 (1:500, AbD Serotec, Kidlington, UK), mouse anti-human $\alpha-S Y N$ (1:500, Abcam, Cambridge, MA, USA), rabbit antihuman $\alpha$-SYN (1:500, Cell Signaling Technology, Danvers, MA, USA), rabbit anti-LC3B (1:200, Abcam, Cambridge, MA, USA), rat anti-LAMP-1 (1:100, DSHB at the University of Iowa, Iowa City, IA, USA), or goat anti-NF-kB p65 (1:100, Santa Cruz Biotechnology, Santa Cruz, CA, USA) followed by a 1:500 dilution of alexa-488 conjugated goat anti-rabbit, goat anti-mouse, donkey anti-rat (Molecular probes, Eugene, OR, USA), a 1:500 dilution of CY3conjugated goat anti-rat, goat anti-rabbit, donkey anti-rabbit, or donkey anti-goat (Jackson Immunoresearch, West Grove, PA, USA) antibodies and $0.05 \mu \mathrm{M}$ SYTOX Green nucleic acid stain (Invitrogen, Carlsbad, CA, USA). Each experimental set was repeated two to three times.

\section{Imaging and quantification}

Confocal images were captured using a Leica TCS-SP5 laser scanning confocal microscope. The images were processed using the Leica software and exported as TIFF files and processed using Adobe Photoshop CS2. For quantitation of NF- $\mathrm{kB}$ p65 staining, the nuclear regions of the cells were defined using SYTOX Green staining, and the p65 intensity was determined using region of interest analysis with ImageJ software (http://rsbweb.nih. gov/ij/). Intensity scores obtained from four images per group (5 to 15 cells in each image) were statistically analyzed using $t$ test.

\section{ELISA}

Conditioned media were collected 2, 4, 8, and $16 \mathrm{~h}$ after the treatment of primary microglia with vehicle or aggregated human $\alpha-S Y N$. The quantities of MIP- $1 \alpha$ were measured with a mouse MIP-1 $\alpha$ ELISA kit (R\&D Systems, Minneapolis, MN, USA) per the manufacturer's instructions. The quantities of TNF were measured with a mouse TNF ELISA kit (eBiosciences, San Diego, CA, USA) per manufacturer's instructions.

\section{Multiplex assay}

Conditioned media were collected $4 \mathrm{~h}$ and $24 \mathrm{~h}$ after the treatment of primary microglia with vehicle or aggregated human $\alpha$-SYN for each of three independent experiments, and analyzed for mouse cytokine and chemokine production on an assay panel with 25 analytes (G-CSF, GM-CSF, IFN- $\gamma$, IL-10, IL-12 (p40), IL-12 (p70), IL-13, IL-15, IL-17, IL-1 $\alpha$, IL-1 $\beta$, IL-2, IL-4, IL-5, IL-6,
IL-7, IL-9, IP-10, KC-like, MCP-1, MIP-1 $\alpha$, MIP-1 $\beta$, MIP-2, RANTES, TNF- $\alpha$ ) per the manufacturer's instructions (Millipore, Billerica, MA, USA).

\section{Results}

Internalization of aggregated human a-SYN by mouse primary microglia

Internalization of aggregated $\alpha$-SYN was studied 24, 48, and $72 \mathrm{~h}$ after the treatment of mouse primary microglia in vitro. Staining for $\alpha$-SYN was performed using an anti-human $\alpha$-SYN specific antibody, together with the microglial marker CD45. In microglia from wild-type animals, there was $\alpha-S Y N$ internalization as early as $24 \mathrm{~h}$, and we observed large dense $\alpha$-SYN aggregates within the microglia at $72 \mathrm{~h}$ (Figure $1 \mathrm{~A}-\mathrm{H}$ ). In general, most microglia contained a single dense aggregate. In microglia derived from $\mathrm{Fc}_{\mathrm{C}} \mathrm{R}^{-1-}$ animals, there was also uptake of the exogenous aggregated human $\alpha-S Y N$, but the pattern of intracellular localization was different. Rather than a single large aggregate, the intracellular $\alpha$-SYN in the $\mathrm{Fc} \gamma \mathrm{R}^{-/-}$microglia was dispersed into a large number of smaller punctate areas of staining. In addition, the intensity of the staining for CD45 was reduced in both vehicle and $\alpha$-SYN-treated Fc $\gamma \mathrm{R}^{-/-}$primary microglia.

To identify the compartments containing $\alpha-S Y N$ in the treated microglia, we performed double staining for $\alpha$-SYN and LC3B, a marker for autophagosomes. At $24 \mathrm{~h}$ post treatment, we observed clear co-localization of $\alpha$-SYN and LC3B within the aggregates in WT primary microglia but not in $\mathrm{Fc}_{\mathrm{R}} \mathrm{R}^{-/-}$microglia (Figure 1I). This result suggests that in WT microglia, the internalized $\alpha-S Y N$ is indeed targeted to autophagosomes, while in the $\mathrm{Fc} \gamma \mathrm{R}^{-/-}$microglia it appears to be trafficked to a set of distinct compartments.

\section{Aggregated human a-SYN triggers NF-KB activation with} nuclear accumulation of p65 protein in microglia

WT mouse primary microglia were treated with either vehicle or $500 \mathrm{nM}$ aggregated human $\alpha$-SYN for $24 \mathrm{~h}$ and $72 \mathrm{~h}$, and immunocytochemistry for NF- $\mathrm{kB}$ p 65 protein was performed to evaluate NF-kB activation in vitro. The cells were stained with SYTOX Green to show the nucleus. Both at $24 \mathrm{~h}$ and $72 \mathrm{~h}, \alpha$-SYN-treated microglia exhibited increased immunoreactivity for NF-kB p65, and the nuclear accumulation of NF- $\mathrm{kB}$ p 65 was quite distinct compared with the vehicle treated cells (Figure $2 \mathrm{~A}$ ). In order to quantify the intensity of nuclear NF- $\mathrm{kB}$ p65, at least four images from each group were analyzed using ImageJ software. The nucleus was circled for ROI selection in the SYTOX Green/NF-kB p65 double staining images, and the nuclear NF- $\mathrm{kB}$ p 65 intensity was obtained under the NF- $\mathrm{kB}$ p65 single channel images. This analysis confirmed the impression of markedly enhanced nuclear NF- $\mathrm{kB}$ p65 staining in the $\alpha$-SYN-treated WT 

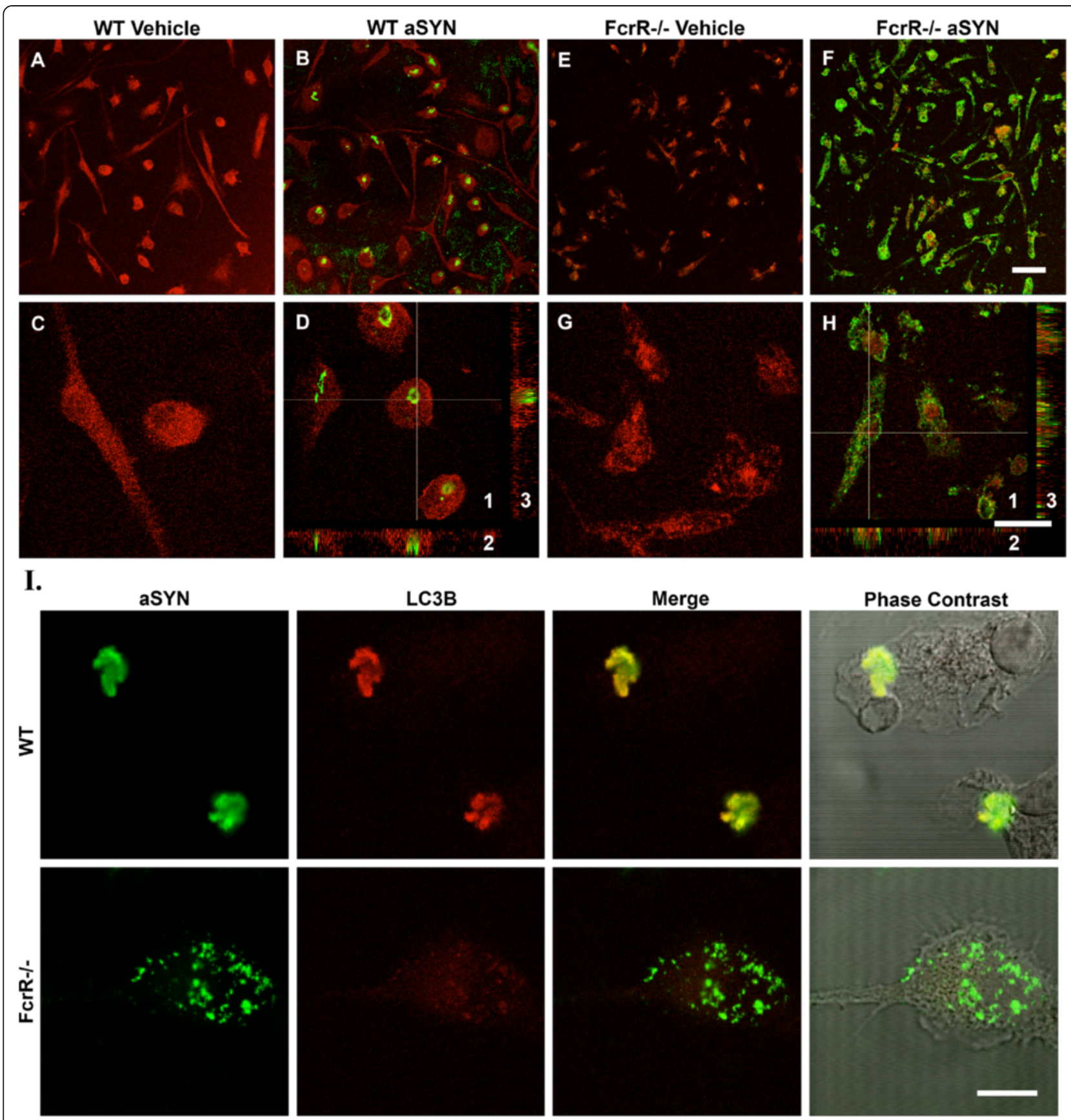

Figure 1 a-SYN internalization in WT and $\mathrm{FcyR}^{-/-}$mouse primary microglia. (A-H) $72 \mathrm{~h}$ after the treatment of aggregated human a-SYN, WT and $\mathrm{F}_{\mathrm{CY}} \mathrm{R}^{-1-}$ mouse primary microglia were immunostained for human a-SYN (Green) and the microglial marker CD45 (Red). Condensed a-SYN was observed in the WT microglia. In FCYR ${ }^{-1-}$ microglia, there was still uptake of aggregated human a-SYN but the pattern of intracellular a-SYN was quite different, with diffuse labeling of small puncta throughout the cytoplasm. Scale bars: panel A, B, E, F bar=50 $\mu$ m; panel C, D, G, $\mathbf{H}$ bar $=20 \mu \mathrm{m}$. Image 1 in Panels $\mathbf{D}$ and $\mathbf{H}$ are confocal images of $\mathrm{WT}$ and $\mathrm{F} c \gamma \mathrm{R}^{-1-}$ mouse primary microglia treated with aggregated human a-SYN, respectively; 2 and 3 in Panel $\mathbf{D}$ and $\mathbf{H}$ are transverse and lengthwise images of z-stack series of the indicated cells. (I) $24 \mathrm{~h}$ after the treatment of aggregated human a-SYN, WT and $\mathrm{FcyR}^{-/-}$mouse primary microglia were immunostained for human a-SYN (Green) and autophagosomal marker LC3B (Red). a-SYN co-localized with LC3B in WT but not FCYR $\mathrm{R}^{-1-}$ microglia. Phase contrast images show the morphology of the cell. Scale bar=10 $\mu \mathrm{m}$. 

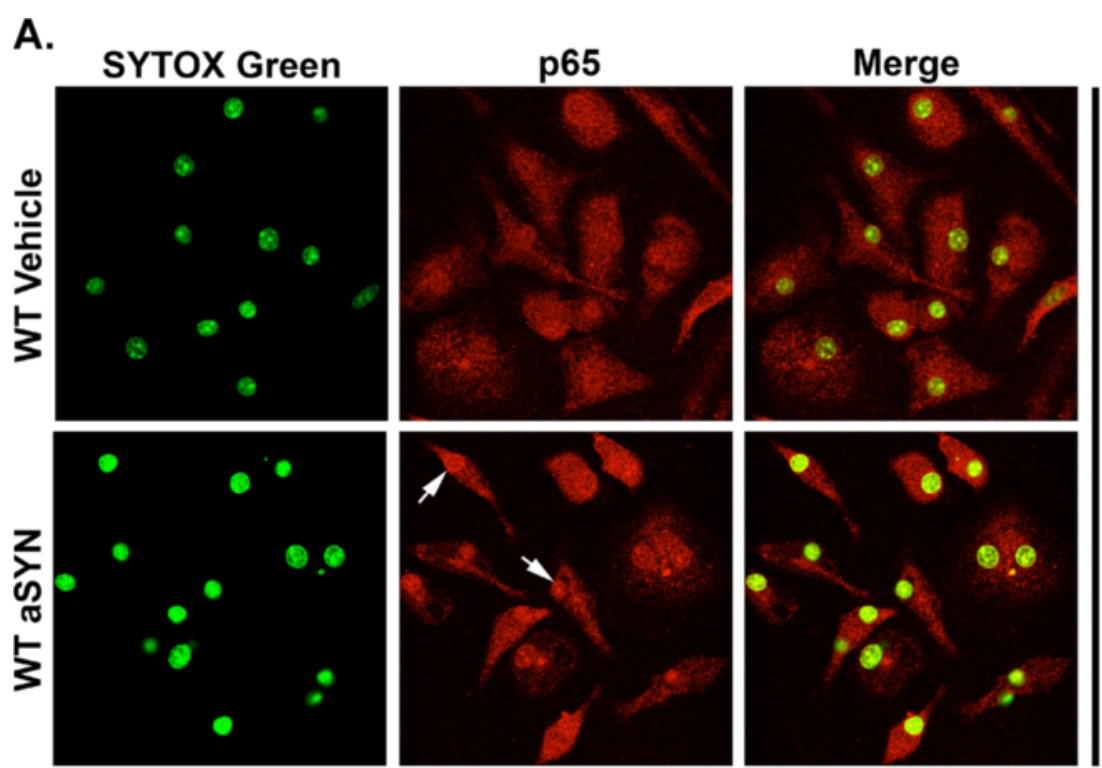

$24 \mathrm{hr}$
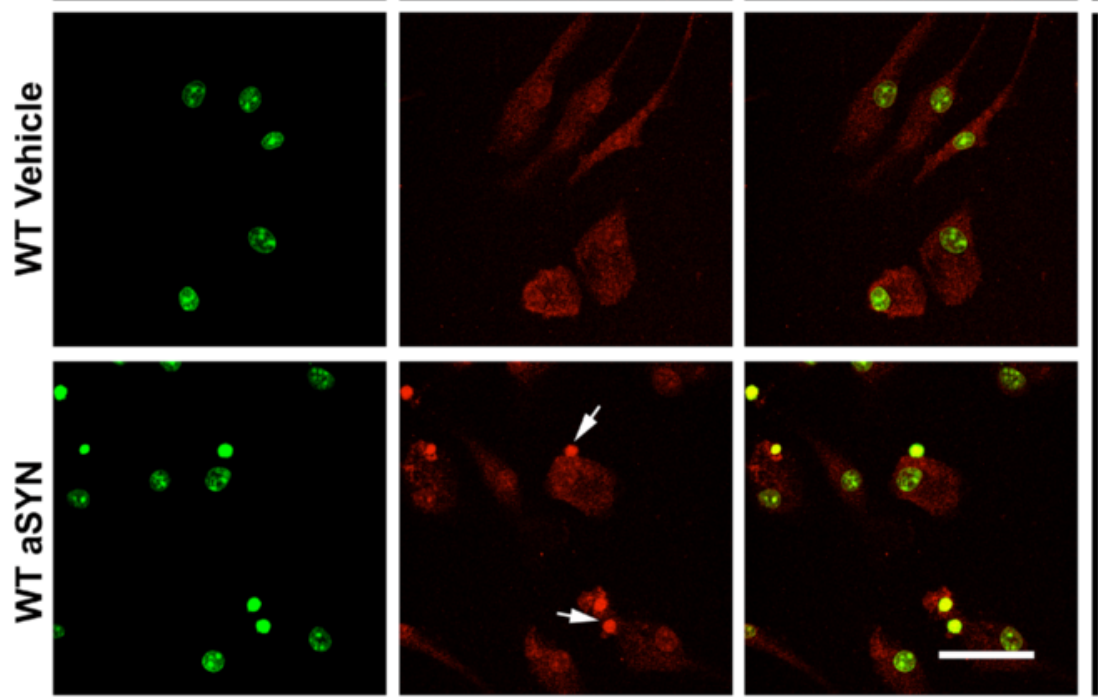

$72 \mathrm{hr}$

B.

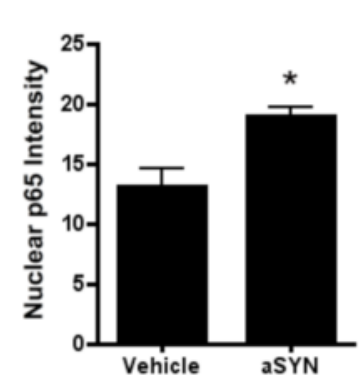

C.

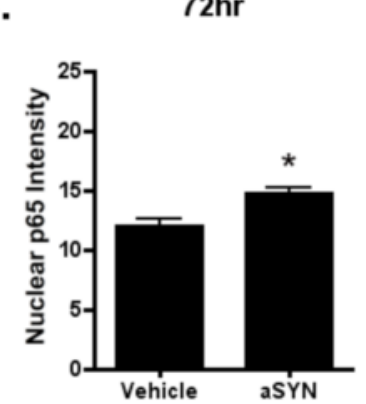

Figure 2 a-SYN-induced NF-KB activation in WT mouse primary microglia. (A) $24 \mathrm{~h}$ and $72 \mathrm{~h}$ after the treatment of either vehicle or $500 \mathrm{nM}$ aggregated human a-SYN, cells were stained for NF-KB p65 protein (Red) and SYTOX Green to show the nucleus. At both time points, a-SYN-treated microglia exhibited increased immunoreactivity for NF-kB p65, and the nuclear accumulation of NF-kB p65 was quite distinct compared with the vehicle treated ones. Scale bar $=40 \mu \mathrm{m}$. Arrows indicate the enrichment of nuclear NF-KB p65. (B, C) Quantification of $24 \mathrm{~h}$ and $72 \mathrm{~h}$ nuclear NF-KB p65 intensity. At least four images from each group were analyzed using ImageJ software. At both time points a-SYN-treated WT microglia had markedly enhanced nuclear NF-KB p65 staining compared with the vehicle-treated controls. ${ }^{*} P<0.05$, a-SYN vs. vehicle, $t$-test. 
microglia compared to the vehicle-treated controls (Figure 2B and C).

\section{$\mathrm{FcyR}^{-/-}$blocks $a-\mathrm{SYN}$-induced nuclear NF-KB p65} accumulation in microglia

We performed the same SYTOX Green/NF-kB p65 double staining for vehicle and $\alpha$-SYN-treated $\mathrm{Fc} \gamma \mathrm{R}^{-/-}$ microglia $24 \mathrm{~h}$ and $72 \mathrm{~h}$ post treatment, and did the same quantification using ImageJ. Compared with WT microglia, vehicle-treated $\mathrm{Fc} \gamma \mathrm{R}^{-/-}$microglia showed a striking increase in nuclear p65 at baseline with intense staining of the nucleus at $24 \mathrm{~h}$ (Figure 3A), and this effect was not seen at $72 \mathrm{~h}$ (data not shown). This is of interest because it parallels the striking increase in nuclear p65 we have previously reported in the $\mathrm{F} c \gamma \mathrm{R}^{-/-}$mice in vivo [15]. After treatment of $\mathrm{Fc} \gamma \mathrm{R}^{-/-}$microglia with aggregated $\alpha-\mathrm{SYN}$, the nuclear prominence of p65 staining was still evident, but quantification of the intensities demonstrated that the nuclear p65 decreased, rather than increased, $24 \mathrm{~h}$ after $\alpha$ SYN treatment (Figure 3B) and there was no significant difference in staining intensity at $72 \mathrm{~h}$ (data not shown).
$\mathrm{Fc}_{\mathrm{C}} \mathrm{R}^{-/-}$attenuates $\mathrm{a}-\mathrm{SYN}$-induced NF-KB signaling and downstream expression of pro-inflammatory molecules In order to investigate the effect of Fc gamma chain deletion on the NF- $\mathrm{kB}$ signaling and the production of cytokines/chemokines regulated by NF- $\mathrm{BB}$, we performed ELISA and multiplexed assay on the conditioned media collected from the vehicle and $\alpha$-SYN-treated primary microglia.

MIP-1 $\alpha$ (Macrophage inflammatory protein-1 $\alpha$ ) is a marker for microglial activation and a target gene regulated by NF-kB [19], therefore we used it to characterize the time course of the effect of aggregated human $\alpha-S Y N$ on pro-inflammatory molecules downstream of NF- $\mathrm{kB}$. Conditioned media were collected $2,4,8$, and 16 h post $\alpha$ SYN treatment of WT microglia and were analyzed for MIP- $1 \alpha$ ELISA. The MIP- $1 \alpha$ level peaked at $4 \mathrm{~h}$ after the human $\alpha-S Y N$ treatment (Figure 4A). Since $\alpha-S Y N$ triggered nuclear p65 enrichment in WT microglia but not $\mathrm{Fc} \gamma \mathrm{R}^{-/-}$microglia at $24 \mathrm{~h}$, we chose $4 \mathrm{~h}$ and $24 \mathrm{~h}$ as the time points for multiplex assay.

Conditioned media were collected $4 \mathrm{~h}$ and $24 \mathrm{~h}$ after the treatment of WT and $\mathrm{F}_{\mathrm{c}} \mathrm{R}^{-/-}$microglia with either vehicle
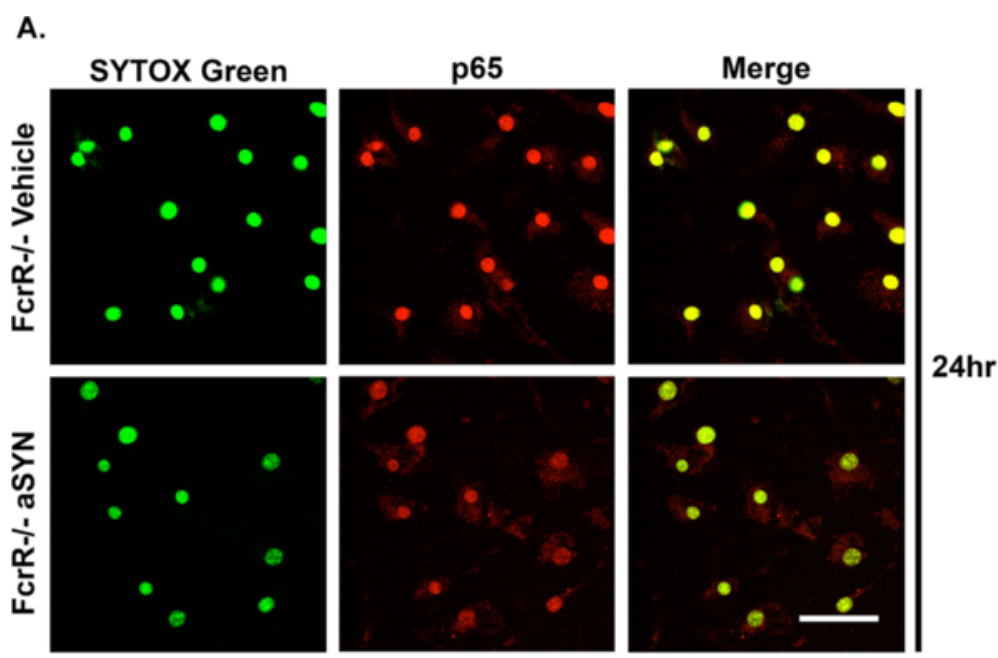

\section{$24 \mathrm{hr}$}

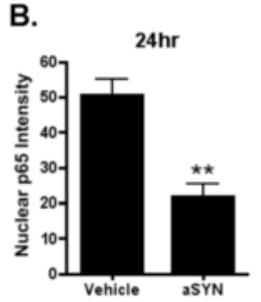

Figure 3 a-SYN-induced NF-KB activation was blocked in $\mathrm{FcYR}^{-/-}$mouse primary microglia. (A) $24 \mathrm{~h}$ after treatment with either vehicle or $500 \mathrm{nM}$ aggregated human a-SYN, FCYR ${ }^{-1}$ microglia were stained for NF-KB p65 protein (Red) and SYTOX Green. a-SYN-treated microglia exhibited attenuated immunoreactivity for NF-KB p65 compared with the vehicle-treated ones. Scale bar $=40 \mu \mathrm{m}$. (B) Quantification of $24 \mathrm{~h}$ nuclear NF-KB p65 intensity. After the treatment of a-SYN, FCYR ${ }^{-1-}$ microglia had a significant decrease in nuclear p65. ${ }^{* *} P<0.01, a-S Y N$ vs. vehicle, t-test. 
A.
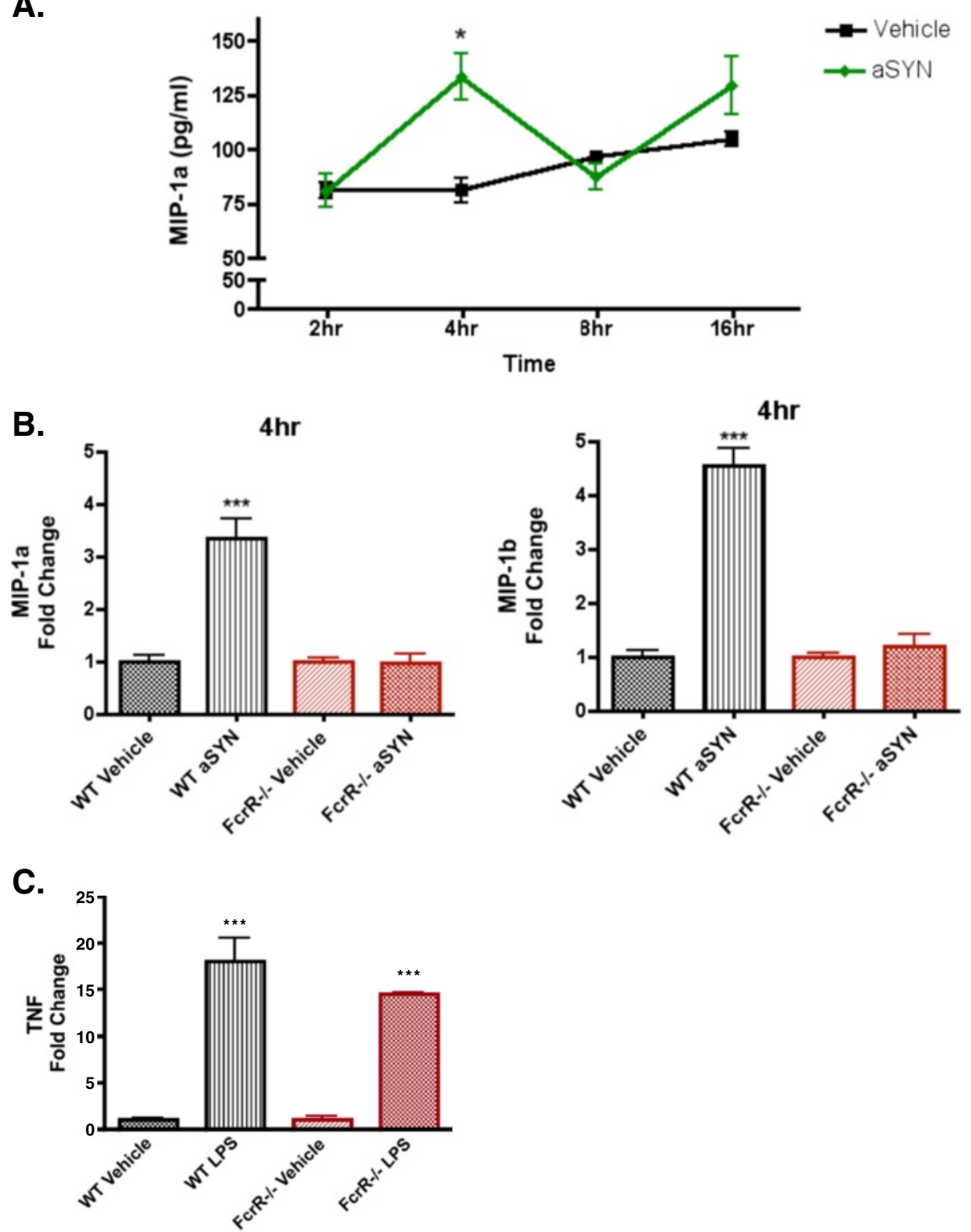

Figure $4 \mathrm{FcyR}^{-/-}$attenuated a-SYN-induced NF-KB signaling and downstream expression of pro-inflammatory molecules. (A) MIP-1a ELISA on the conditioned media collected 2, 4, 8, and $16 \mathrm{~h}$ from the vehicle and a-SYN-treated WT primary microglia. At $4 \mathrm{~h}$, but not the other time points, the MIP-1a level was significantly increased with a-SYN treatment compared with the vehicle controls. ${ }^{*} P<0.05$, $a-S Y N$ vs. vehicle, $t$-test. (B) Conditioned media were collected $4 \mathrm{~h}$ and $24 \mathrm{~h}$ after the treatment of vehicle or aggregated human a-SYN on WT and FcyR ${ }^{-/-}$ microglia for a 25-plex mouse cytokine/chemokine assay. At 4 h, MIP-1a and MIP-1 $\beta$ were significantly increased with a-SYN treatment in WT microglia but not $\mathrm{F}_{\mathrm{c} y \mathrm{R}^{-1-}}$ microglia compared with vehicle-treated ones. All chemokine expression levels were normalized to the level of vehicletreated WT or $\mathrm{FcyR}^{-1-}$ microglia, respectively. ${ }^{* *} \mathrm{P}<0.001 \mathrm{WT}$ a-SYN vs. WT vehicle. One-way ANOVA with Tukey's multiple comparison test. (C) Conditioned media collected from primary WT and $\mathrm{FcyR}^{-/-}$microglia treated overnight with $100 \mathrm{ng} / \mathrm{mL}$ LPS. Both WT and FcyR ${ }^{-/-}$microglia respond normally to TLR4 stimulation. TNF expression levels were normalized to the level of vehicle-treated WT or FcyR ${ }^{-1-}$ microglia, respectively. ***P $<0.001$ WT LPS vs. WT vehicle, FcyR ${ }^{-/-}$LPS vs. FcyR ${ }^{-/-}$vehicle. One-way ANOVA with Tukey's multiple comparison test.

or aggregated human $\alpha$-SYN, and studied using a 25-plex mouse cytokine/chemokine assay. To our surprise, there was only a limited cytokine response, with detectable levels of IL-1 $\alpha$, IP-10, MIP-1 $\alpha$, MIP-1 $\beta$, MIP-2, MCP-1 at $4 \mathrm{~h}$ and $24 \mathrm{~h}$. Other pro-inflammatory cytokines such as
TNF- $\alpha$ or IL-6 were not detectable $(<10 \mathrm{pg} / \mathrm{mL})$ in the multiplex assay (Table 1 ). At $4 \mathrm{~h}$, MIP- $1 \alpha$ and MIP-1 $\beta$ were significantly increased with $\alpha-S Y N$ treatment in WT microglia compared with vehicle-treated cells, nevertheless, this increase was not observed in $\alpha-S Y N$-treated Fc $\gamma R^{-/-}$ 
Table 1 Effects of FcyR-/- on a-SYN-induced pro-inflammatory molecules

\begin{tabular}{|c|c|c|c|c|c|c|c|c|}
\hline \multirow[t]{2}{*}{ Fold } & \multicolumn{4}{|c|}{$4 \mathrm{~h}$} & \multicolumn{4}{|c|}{$24 \mathrm{~h}$} \\
\hline & WT vehicle & WT a-SYN & $\mathrm{Fc}_{\mathrm{R}} \mathrm{R}^{-/-}$vehicle & $\mathrm{FcyR}^{-/-} \mathrm{a}-\mathrm{SYN}$ & WT vehicle & WT a-SYN & $\mathrm{Fc}_{\mathrm{R}} \mathrm{R}^{-/-}$vehicle & $\mathrm{Fc \gamma R}^{-1-} \mathrm{a}-\mathrm{SYN}$ \\
\hline IL-1a & $1.00 \pm 0.48$ & $3.32 \pm 2.45$ & $1.00 \pm 0.21$ & $0.55 \pm 0.22$ & $1.00 \pm 0.17$ & $1.05 \pm 0.23$ & $1.00 \pm 0.20$ & $1.03 \pm 0.42$ \\
\hline IP-10 & $1.00 \pm 0.21$ & $5.29 \pm 2.93$ & $1.00 \pm 0.41$ & $0.79 \pm 0.38$ & $1.00 \pm 0.23$ & $1.01 \pm 0.34$ & $1.00 \pm 0.07$ & $1.79 \pm 0.42$ \\
\hline MIP-1a & $1.00 \pm 0.21$ & $3.35 \pm 0.61^{a}$ & $1.00 \pm 0.11$ & $0.97 \pm 0.39$ & $1.00 \pm 0.09$ & $1.29 \pm 0.35$ & $1.00 \pm 0.31$ & $2.07 \pm 0.93$ \\
\hline$\overline{M I P-1 \beta}$ & $1.00 \pm 0.23$ & $4.54 \pm 0.56^{a}$ & $1.00 \pm 0.15$ & $1.19 \pm 0.45$ & $1.00 \pm 0.08$ & $1.26 \pm 0.38$ & $1.00 \pm 0.46$ & $2.91 \pm 1.55$ \\
\hline MIP-2 & & nd & & & $1.00 \pm 0.20$ & $1.37 \pm 0.21$ & $1.00 \pm 0.46$ & $1.40 \pm 0.75$ \\
\hline MCP-1 & & nd & & & $1.00 \pm 0.12$ & $1.24 \pm 0.37$ & $1.00 \pm 0.31$ & $1.88 \pm 1.10$ \\
\hline
\end{tabular}

microglia (Figure 4B). To determine if $\mathrm{Fc} \gamma \mathrm{R}^{-/-}$microglia can respond normally to pathogen associated molecular patterns (PAMPs) involved in the NF-kB-dependent proinflammatory response, primary WT and $\mathrm{Fc}_{\mathrm{C}} \mathrm{R}^{-/-}$microglia were plated and treated overnight with $100 \mathrm{ng} / \mathrm{mL}$ lipopolysaccharide (LPS), a Toll-like receptor 4 (TLR4) specific ligand. Conditioned media were collected and analyzed for TNF expression by ELISA. Following LPS treatment, we found no difference in amount of TLR4specific TNF induction between the WT and $\mathrm{Fc}_{\mathrm{C}} \mathrm{R}^{-/-}$ microglia (Figure 4C) indicating that $\mathrm{Fc}_{\mathrm{C}} \mathrm{R}^{-/-}$microglia can respond normally to pro-inflammatory stimuli.

\section{Discussion}

Our studies have shown that aggregated $\alpha-S Y N$ can interact directly with microglia, and can be internalized and condensed within these cells. With $\alpha$-SYN treatment, there is enrichment of the NF- $\kappa B$ component p65 in the nucleus of microglia. Meanwhile, downstream chemokines regulated by NF- $\kappa$ B including MIP- $1 \alpha$ and MIP- $1 \beta$ show increased expression levels. Deficiency of gamma chain subunit of the Fc receptors alters the pattern of internalized $\alpha$-SYN so that it is no longer condensed in autophagosomes. It prevents microglial nuclear p65 accumulation, and blocks $\alpha$-SYNinduced changes in chemokine expression.

In the mouse, the classic FcyRs are well characterized and include Fc $\gamma R$ I, FcyRIIB, and FcyRIII. Both Fc $\gamma$ RI and Fc $\gamma$ RIII are multi-chain complexes composed of a single ligand-binding $\alpha$-chain and a homodimer of common gamma-chains that mediates intracellular signaling through an immuno-receptor tyrosine-based activation motif (ITAM) in the cytoplasmic domain [20]. The $\mathrm{Fc}_{\mathrm{C}} \mathrm{R}^{-1-}$ mice that we used in our studies are deficient in the gamma chain subunit of the Fc receptors, therefore the functional expression of $\mathrm{Fc \gamma RI}$ and FcyRIII is greatly diminished, and the activated $\mathrm{F} c \gamma \mathrm{R}^{-/-}$microglia lack the ability to phagocytose antibody-coated particles even with the retention of FcyRIIB [16]. Thus, although our data clearly implicate receptors containing the Fc gamma chain, they do not allow us to distinguish between effects mediated by FcyRI or Fc $\gamma$ RIII, and it is possible that either, both, or additional scavenger receptors are involved in the $\alpha$-SYN-induced neuroinflammation.

We have previously characterized the responses to $\alpha$ SYN in vivo using an AAV-synuclein mouse model of PD [15]. We found that with the targeted overexpression of human $\alpha-S Y N$ in the SN of WT mice, there is microglial activation and marked accumulation of p65 protein in the nucleus of microglia, and downstream activation of NF$\mathrm{kB}$-driven pro-inflammatory mediators can be detected. In $\mathrm{Fc}_{\mathrm{R}} \mathrm{R}^{-/-}$mice, microglial nuclear p65 accumulation and transcriptional induction of the pro-inflammatory mediators in response to overexpression of $\alpha$-SYN are blocked in vivo. Moreover, $\alpha$-SYN-trigged dopaminergic neurodegeneration is attenuated. Our in vitro studies are consistent with these in vivo results, showing that excess $\alpha$-SYN leads to microglial NF- $\mathrm{kB}$ activation and downstream proinflammatory signaling, and the gamma chain subunit of the Fc receptors is essential for this process. We also have observed both in vivo and in vitro that the $\mathrm{Fc} \gamma \mathrm{R}^{-1-}$ mice have much greater baseline abundance of nuclear p65 (Figure 3). Both in vivo and in vitro, we have found that $\alpha-S Y N$ induces a marked enhancement of nuclear p65 and activates NF- $\mathrm{kB}$ signaling, while in the absence of Fc gamma chain, $\alpha$-SYN leads to a modest reduction in nuclear p65 (which is elevated at baseline) and does not trigger expression of NF-kB-dependent transcripts.

Using the in vitro approach, we have been able to investigate directly the interaction between aggregated $\alpha$ SYN and microglia. We have found that $\alpha-S Y N$ is internalized by microglia and concentrated in autophagosomes. As this $\alpha$-SYN internalization occurs in the absence of any antibody mediation, this must represent a form of IgG-independent phagocytosis. The process of IgG-independent phagocytosis plays a critical role in the early response to infection, and is an important part of the innate immune system [21]. IgG-independent phagocytosis can be triggered by several different molecules expressed on the cell surface, such as scavenger receptors and complement receptors [21,22]. IgG- 
independent phagocytosis has been previously reported with $\alpha-S Y N$ [23], and can also be mediated by Fc $\gamma$ Rs through interaction with alternative ligands including complement receptors and c-reactive proteins [12-14]. A recent study in Alzheimer's disease showed that complement receptor type 3 (CR3), which is a receptor for soluble FcyRIII, contributes to the phagocytosis and clearance of fibrillar $A \beta$ by microglia, and the internalized $A \beta$ is transported to lysosomes in microglia [12,24].

Internalization of $\alpha$-SYN was observed in both WT and $\mathrm{F}_{\mathrm{C}} \mathrm{R}^{-/-}$microglia, but the intracellular destinations of the internalized protein were different. In WT microglia, $\alpha-\mathrm{SYN}$ is trafficked to autophagosomes, as demonstrated by the co-localization with LC3. This is consistent with earlier work showing autophagocytic protein is localized in Lewy bodies [25], and that the engagement of FcyRs during phagocytosis induces recruitment of the autophagy protein LC3 to phagosomes [26]. In the $\mathrm{Fc} \gamma \mathrm{R}^{-/-}$microglia with deficiency of the gamma chain subunit of Fc receptors, however, the pattern of $\alpha$-SYN internalization is altered, with a much more diffuse localization. In an effort to identify the compartments with $\alpha$-SYN staining in the $\mathrm{Fc}_{\mathrm{C}} \mathrm{R}^{-/-}$microglia, we performed double staining for $\alpha-S Y N$ and lysosomal marker LAMP-1 but did not observe evidence for co-localization in either WT or Fc $\mathrm{RR}^{-/-}$ microglia (data not shown). While the location of $\alpha$-SYN in the $\mathrm{Fc} \gamma \mathrm{R}^{-/-}$microglia is uncertain, it is possible that it still involves Fc receptors. Deletion of the gamma chain results in complete loss of FcyRIII function and marked reduction of FcyRI, while Fc $\gamma$ RII receptors are unaffected. There are previous studies suggesting that FcyRII may target proteins to recycling pathways, and it is possible that a similar process is at work in the gamma chain deficient microglia [27].

Although we did observe a direct effect of aggregated $\alpha$-SYN on NF- $\kappa B$-mediated chemokine expression, the extent of this response was limited and pro-inflammatory cytokines like TNF- $\alpha$ or IL- 6 were not detectable at both $4 \mathrm{~h}$ and $24 \mathrm{~h}$ in the multiplex assay. This differs somewhat from prior studies in which a broader cytokine and chemokine response has been observed in vitro. These differences may arise in part because of the antigen employed; most prior studies used with mutant or nitrated $\alpha$-SYN $[28,29]$, or very high concentrations of wild-type $\alpha$-SYN (up to $10 \mu \mathrm{M}$ [30]). On the other hand, in our in vivo studies in the AAV-synuclein mouse model of PD, we did find a broad pattern of cytokine induction, with significant increases in the expression level of TNF- $\alpha$, IL-6, and IL-1 $\alpha$ [11]. The differences between the in vitro and in vivo responses point to the possibility that the microglial response may not be entirely cell-autonomous, and may require interactions with other cell types including $\mathrm{T}$ cell populations, which are known to be present in the brain in both the AAV model of PD as well as in the human disease $[5,11]$.

\section{Conclusions}

In summary, our data provide evidence that $\alpha$-SYN can interact directly with microglia to induce proinflammatory signaling, and $\mathrm{Fc} \gamma \mathrm{R}$ proteins mediate $\alpha-\mathrm{SYN}$ intracellular trafficking and pro-inflammatory signaling. Therefore, inhibition of either Fc $\gamma \mathrm{R}$ signaling or downstream NF- $\mathrm{kB}$ activation may be viable therapeutic strategies to slow or prevent the progression of human PD.

\section{Additional file}

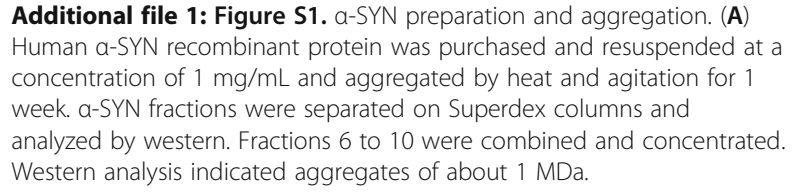

Additional file 1: Figure S1. a-SYN preparation and aggregation. (A) Human a-SYN recombinant protein was purchased and resuspended at a concentration of $1 \mathrm{mg} / \mathrm{mL}$ and aggregated by heat and agitation for 1 week. a-SYN fractions were separated on Superdex columns and analyzed by western. Fractions 6 to 10 were combined and concentrated. Western analysis indicated aggregates of about $1 \mathrm{MDa}$.

\section{Abbreviations}

a-SYN: Alpha-synuclein; AAV: Adeno-associated virus; DA: Dopamine; FcyR: Fc gamma receptor; IgG: Immunoglobulin G; LPS: Lipopolysaccharide; NF-KB: Nuclear factor kappa-light-chain-enhancer of activated B cells; PAMPs: Pathogen associated molecular patterns; PD: Parkinson's disease; SNpc: Substantia nigra pars compacta.

\section{Competing interests}

The authors declare that they have no competing interests.

\section{Authors' contributions}

SC carried out ELISA, multiplex assay and data analysis, participated in the design of the study, primary microglia culture and immunocytochemistry, and drafted the manuscript. DS participated in the design of the study and helped to draft the manuscript. AH participated in the design of the study, primary microglia culture and immunocytochemistry, and helped to draft the manuscript. All authors read and approved the final manuscript.

\section{Acknowledgements}

We appreciate the help from Dr. Chad Steele's lab for multiplex assay in UAB. This work was supported by the APDA Advanced Center for Parkinson Research at UAB.

Received: 28 June 2012 Accepted: 3 November 2012 Published: 27 November 2012

\section{References}

1. Spillantini MG, Schmidt ML, Lee VM, Trojanowski JQ, Jakes R, Goedert M: Alpha-synuclein in Lewy bodies. Nature 1997, 388:839-840.

2. Hardy J, Cai H, Cookson MR, Gwinn-Hardy K, Singleton A: Genetics of Parkinson's disease and parkinsonism. Ann Neurol 2006, 60:389-398.

3. Polymeropoulos MH, Lavedan C, Leroy E, Ide SE, Dehejia A, Dutra A, Pike B, Root H, Rubenstein J, Boyer R, Stenroos ES, Chandrasekharappa S, Athanassiadou A, Papapetropoulos T, Johnson WG, Lazzarini AM, Duvoisin RC, Di lorio G, Golbe LI, Nussbaum RL: Mutation in the alpha-synuclein gene identified in families with Parkinson's disease. Science 1997, 276:2045-2047.

4. McGeer PL, Itagaki S, Boyes BE, McGeer EG: Reactive microglia are positive for HLA-DR in the substantia nigra of Parkinson's and Alzheimer's disease brains. Neurology 1988, 38:1285-1291.

5. Brochard V, Combadiere B, Prigent A, Laouar Y, Perrin A, Beray-Berthat V Bonduelle O, Alvarez-Fischer D, Callebert J, Launay JM, Duyckaerts C, Flavell RA, Hirsch EC, Hunot S: Infiltration of CD4+ lymphocytes into the brain contributes to neurodegeneration in a mouse model of Parkinson disease. J Clin Invest 2009, 119:182-192.

6. McGeer PL, Schwab C, Parent A, Doudet D: Presence of reactive microglia in monkey substantia nigra years after 1-methyl-4-phenyl-1,2,3,6tetrahydropyridine administration. Ann Neurol 2003, 54:599-604. 
7. Hirsch EC, Hunot S: Neuroinflammation in Parkinson's disease: a target for neuroprotection? Lancet Neurol 2009, 8:382-397.

8. Ahmed I, Tamouza R, Delord M, Krishnamoorthy R, Tzourio C, Mulot C, Nacfer M, Lambert JC, Beaune P, Laurent-Puig P, Loriot MA, Charron D, Elbaz A: Association between Parkinson's disease and the HLA-DRB1 locus. Mov Disord 2012, 27:1104-1110.

9. Simon-Sanchez J, Schulte C, Bras JM, Sharma M, Gibbs JR, Berg D, PaisanRuiz C, Lichtner P, Scholz SW, Hernandez DG, Kruger R, Federoff M, Klein C, Goate A, Perlmutter J, Bonin M, Nalls MA, Illiq T, Gieger C, Houlden H, Steffens M, Okun MS, Racette BA, Cookson MR, Foote KD, Fernandez HH, Traynor BJ, Schreiber S, Arepalli S, Zonozi R, et al: Genome-wide association study reveals genetic risk underlying Parkinson's disease. Nat Genet 2009, 41:1308-1312.

10. Hamza TH, Zabetian CP, Tenesa A, Laederach A, Montimurro J, Yearout D, Kay DM, Doheny KF, Paschall J, Pugh E, Kusel VI, Collura R, Roberts J, Griffith A, Samii A, Scott WK, Nutt J, Factor SA, Payami H: Common genetic variation in the HLA region is associated with late-onset sporadic Parkinson's disease. Nat Genet 2010, 42:781-785.

11. Theodore S, Cao S, McLean PJ, Standaert DG: Targeted overexpression of human alpha-synuclein triggers microglial activation and an adaptive immune response in a mouse model of Parkinson disease. J Neuropathol Exp Neurol 2008, 67:1149-1158.

12. Galon J, Gauchat JF, Mazieres N, Spagnoli R, Storkus W, Lotze M, Bonnefoy JY, Fridman WH, Sautes C: Soluble Fcgamma receptor type III (FcgammaRIII, CD16) triggers cell activation through interaction with complement receptors. J Immunol 1996, 157:1184-1192.

13. Stein MP, Mold C, Du Clos TW: C-reactive protein binding to murine leukocytes requires Fc gamma receptors. J Immunol 2000, 164:1514-1520.

14. Okun E, Mattson MP, Arumugam TV: Involvement of Fc receptors in disorders of the central nervous system. Neuromolecular Med 2010, 12:164-178

15. Cao $S$, Theodore $S$, Standaert DG: Fcgamma receptors are required for NF-kappaB signaling, microglial activation and dopaminergic neurodegeneration in an AAV-synuclein mouse model of Parkinson's disease. Mol Neurodegener 2010, 5:42.

16. Takai T, Li M, Sylvestre D, Clynes R, Ravetch JV: FcR gamma chain deletion results in pleiotrophic effector cell defects. Cell 1994, 76:519-529.

17. Lee JK, McCoy MK, Harms AS, Ruhn KA, Gold SJ, Tansey MG: Regulator of G-protein signaling 10 promotes dopaminergic neuron survival via regulation of the microglial inflammatory response. J Neurosci 2008, 28:8517-8528.

18. Zhang W, Wang T, Pei Z, Miller DS, Wu X, Block ML, Wilson B, Zhou Y, Hong JS, Zhang J: Aggregated alpha-synuclein activates microglia: a process leading to disease progression in Parkinson's disease. FASEB J 2005, 19:533-542.

19. Rezzonico R, Imbert $V$, Chicheportiche R, Dayer JM: Ligation of CD11b and CD11c beta(2) integrins by antibodies or soluble CD23 induces macrophage inflammatory protein 1alpha (MIP-1alpha) and MIP-1beta production in primary human monocytes through a pathway dependent on nuclear factor-kappaB. Blood 2001, 97:2932-2940.

20. Szalai AJ, Hu X, Raman C, Barnum SR: Requirement of the Fc receptor common gamma-chain for gamma delta T cell-mediated promotion of murine experimental autoimmune encephalomyelitis. Eur J Immunol 2005, 35:3487-3492

21. Webster ML, Zhu G, Li Y, Ni H: Fc-independent phagocytosis: implications for intravenous lgG therapy in immune thrombocytopenia. Cardiovasc Hematol Disord Drug Targets 2008, 8:278-282.

22. Gu C, Jenkins SA, Xue Q, Xu Y: Activation of the Classical Complement Pathway by Bacillus anthracis Is the Primary Mechanism for Spore Phagocytosis and Involves the Spore Surface Protein BcIA. J Immunol 2012, 188:4421-4431.

23. Su X, Maguire-Zeiss KA, Giuliano R, Prifti L, Venkatesh K, Federoff HJ: Synuclein activates microglia in a model of Parkinson's disease. Neurobiol Aging 2008, 29:1690-1701

24. Fu H, Liu B, Frost JL, Hong S, Jin M, Ostaszewski B, Shankar GM, Costantino IM, Carroll MC, Mayadas TN, Lemere CA: Complement component C3 and complement receptor type 3 contribute to the phagocytosis and clearance of fibrillar Abeta by microglia. Glia 2012, 60:993-1003.

25. Odagiri S, Tanji K, Mori F, Kakita A, Takahashi H, Wakabayashi K: Autophagic adapter protein NBR1 is localized in Lewy bodies and glial cytoplasmic inclusions and is involved in aggregate formation in alphasynucleinopathy. Acta Neuropathol 2012, 124:173-186.

26. Huang J, Canadien V, Lam GY, Steinberg BE, Dinauer MC, Magalhaes MA, Glogauer M, Grinstein S, Brumell JH: Activation of antibacterial autophagy by NADPH oxidases. Proc Natl Acad Sci USA 2009, 106:6226-6231.

27. Zhang CY, Booth JW: Divergent intracellular sorting of Fc\{gamma\}RIIA and Fc\{gamma\}RIIB2. J Biol Chem 2010, 285:34250-34258.

28. Reynolds AD, Glanzer JG, Kadiu I, Ricardo-Dukelow M, Chaudhuri A, Ciborowski P, Cerny R, Gelman B, Thomas MP, Mosley RL, Gendelman HE: Nitrated alpha-synuclein-activated microglial profiling for Parkinson's disease. J Neurochem 2008, 104:1504-1525.

29. Roodveldt C, Labrador-Garrido A, Gonzalez-Rey E, Fernandez-Montesinos R, Caro M, Lachaud CC, Waudby CA, Delgado M, Dobson CM, Pozo D: Glial innate immunity generated by non-aggregated alpha-synuclein in mouse: differences between wild-type and Parkinson's disease-linked mutants. PLoS One 2010, 5:e13481.

30. Lee EJ, Woo MS, Moon PG, Baek MC, Choi IY, Kim WK, Junn E, Kim HS: Alpha-synuclein activates microglia by inducing the expressions of matrix metalloproteinases and the subsequent activation of proteaseactivated receptor-1. J Immunol 2010, 185:615-623.

doi:10.1186/1742-2094-9-259

Cite this article as: Cao et al:: The gamma chain subunit of Fc receptors is required for alpha-synuclein-induced pro-inflammatory signaling in microglia. Journal of Neuroinflammation 2012 9:259.

\section{Submit your next manuscript to BioMed Central and take full advantage of:}

- Convenient online submission

- Thorough peer review

- No space constraints or color figure charges

- Immediate publication on acceptance

- Inclusion in PubMed, CAS, Scopus and Google Scholar

- Research which is freely available for redistribution
C) BioMed Central 